\title{
Articular surface mounted navigated total knee arthroplasty improves the reliability of component alignment
}

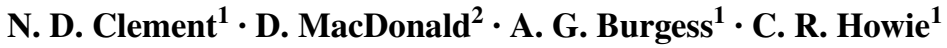

Received: 13 September 2016 / Accepted: 16 January 2017 / Published online: 16 February 2017

(C) The Author(s) 2017. This article is published with open access at Springerlink.com

\begin{abstract}
Purpose The primary aim was to compare the early kneespecific functional outcome after articular surface mounted (ASM) navigation with non-navigated TKA. The secondary aims were to compare general physical and mental health improvement, patient satisfaction, and reliability of component alignment in the sagittal and coronal planes between ASM navigated TKA with that of non-navigated TKA.

Methods Prospective functional outcome and radiographic data were collect for 123 patients undergoing ASM navigation and 172 patients undergoing non-navigated TKA by a high volume single surgeon. Pre-operative and one-year Oxford knee score (OKS) and short form (SF-) 12 scores were collected. Patient satisfaction was also assessed at one year. Implant position was assessed on post-operative radiographs (alpha, beta, gamma, and sigma angles) by a blinded observer.

Results There was no significant difference for improvement in OKS, SF-12 physical or mental components, or satisfaction between the groups one year following surgery. The non-navigation group was significantly more likely to have outliers (greater than 3 degrees) in femoral varus/ valgus coronal alignment [odds ratio (OR) 4.5 , 95\% confidence interval (CI) 1.0-20.7, $p=0.049$ ] and for posterior tibial slope (OR 8.3, 95\% CI 1.1-65.0, $p=0.03$ ).

Conclusions ASM navigation significantly reduces the number of outliers for the femoral and tibial components
\end{abstract}

N. D. Clement

nickclement@doctors.org.uk

1 Department of Orthopaedics and Trauma, The Royal Infirmary of Edinburgh, Little France, Edinburgh EH16 4SA, UK

2 University of Edinburgh, Edinburgh, UK when compared to conventional non-navigation alignment. However, the short-term functional outcome is not influenced by the surgical technique used. If the surgeon wants to reduce their number of outliers, then ASM navigation should be considered but the overall functional outcome in the short term is not influenced.

Level of evidence III Therapeutic investigation, retrospective cohort study.

Keywords Total knee arthroplasty · Navigation .

Outcome $\cdot$ Alignment $\cdot$ Oxford knee score

\section{Introduction}

Approximately, one in five patients are not satisfied with their total knee arthroplasty (TKA) [1], and one reason may be implant malalignment during surgery that could result in early revision for instability [2]. Over the last 20 years, there have been numerous publications supporting the increased accuracy of computer navigation over conventional instrumentation for TKA [3-5], however the uptake of this technology is not widespread [6]. Several level one studies have demonstrated that navigation for TKA results in less deviation from the mechanical axis, being more likely to be within three degrees of the planned coronal alignment [7-9]. It is also interesting to note that one of the most successful litigations after TKA is for technical errors such as malalignment (71\%) [10].

Navigated TKA does have specific complications associated with the use of tracker pins. There have been several reports of peri-prosthetic fractures from the tracker pin sites $[11,12]$. There has also been concerns regarding tracker movement during surgery especially in osteoporotic bone [13] and with use of a single pin [14]. Stability is most 
reliable when three pins are used in the metaphysis [15]; this may, however, increase the fracture risk from numerous cortical perforations. An articular surface mounted (ASM) tracker avoids any cortical deficits in the metaphysis and affords greater stability using four pins to secure the tracker placement. The authors are only aware of three published studies in the literature reporting the outcome of ASM navigation for TKA [15-17]. A randomised controlled trial by Harvie et al. [18] demonstrated ASM navigation to be as accurate as full navigation and that the operative time was significantly reduced. A retrospective comparative study illustrated the femoral component alignment to be more accurate with ASM navigation compared to conventional intramedullary instrumentation [19]. Despite this increased accuracy of the femoral component with ASM navigation, the functional outcome of the TKA is no different to that of a conventional intramedullary instrumentation [20].

The primary aim of this study was to compare the early knee-specific functional outcome after ASM navigation with non-navigated TKA. The secondary aims were to compare general physical and mental health improvement, patient satisfaction, and reliability of component alignment between ASM navigated TKA with that of non-navigated TKA. The hypothesis of the study was that navigation offers greater accuracy of component alignment with improved functional outcomes when compared to non-navigated TKA.

\section{Materials and methods}

A retrospective cohort study was conducted. During a seven-year period (2007-2013), patients undergoing a TKA at the study centre by the senior author (CRH) had outcome data recorded prospectively. Inclusion criterion for this study were: primary osteoarthritis, no extra-articular deformity or reason why an intramedullary jig could not be used. Patients undergoing consecutive bilateral TKAs during the study period only had outcome and radiographic measures assessed for their first knee.

The patient demographics, ASA grade, body mass index (BMI) and patient reported outcome measures were recorded at the pre-operative assessment clinic. Oxford knee score (OKS) [21] and the short form (SF-) 12 score [22] were recorded pre-operatively and at one year post-operatively. The OKS consists of twelve questions assessed on a Likert scale with values from 0 to 4 , a summative score is then calculated where 48 is the best possible score (least symptomatic) and 0 is the worst possible score (most symptomatic). The SF-12 is a generic assessment tool to measure a patients wellbeing, which is assessed using a physical component summary (PCS) and a mental component summary (MCS) [22]. Both the SF-12 PCS and MCS range from 0\% (worst level of functioning) to $100 \%$ (best level of functioning). Patient satisfaction was assessed by asking the question "How satisfied are you with your operated knee?" 1 year after surgery. The response was recorded using a four-point Likert scale: very satisfied, satisfied, uncertain, and unsatisfied. Patients who recorded very satisfied or satisfied were classified as satisfied. This has been used previously to assess patient satisfaction after TKA [1].

Radiographic assessment was performed using standard weight bearing anterior-posterior and lateral radiographs. The included patients did not have any extraarticular deformity and there was no clinical need to obtain a hip knee ankle (HKA) radiograph, which is the gold standard for measuring alignment. The circle method described by Veljkovic et al. [23] and validated for use around the knee by Zampogna et al. [24] was used to assess implant alignment. Alpha, beta, gamma, and sigma angles, as described by Shah et al. [19], were measured using digital radiographs $\left(\operatorname{Kodac}^{\odot}\right.$ picture archiving and communication system on a liquid crystal display) and the graphic measuring tools available to one decimal place (Fig. 1).

There was a randomised controlled trial conducted at the study centre from 2008 to 2010 and patients recruited to this were removed from the presented cohort [25]. During the study period, the senior author performed or scrub-supervised all included TKAs. All patients underwent a cemented Triathlon $\left(\right.$ Stryker $\left.{ }^{\circledR}\right)$ TKA using a measured resection technique. The technique (ASM navigation or conventional jig alignment) was assigned according to availability of surgical trays for patients who met the inclusion criterion. The primary technique was ASM navigation, but if the trays were not available for this conventional instrumentation was used. A mid-line medial para-patellar approach was made in all patients. ASM navigation was used for both femoral and tibial

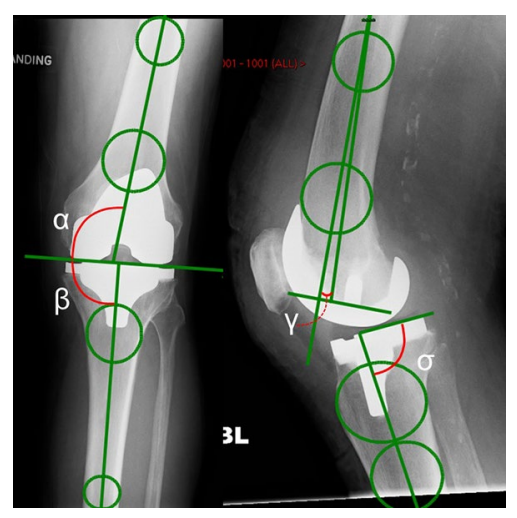

Fig. 1 Anterior-posterior and lateral radiograph of the knee post operatively illustrating the angles measured $(\alpha, \beta, \gamma$, and $\sigma)$ 
alignment; however, sizing of the femoral component and rotation (using Whiteside's line [26]) was performed manually. The femoral component was aligned in $6^{\circ}$ valgus and neutral flexion/extension (at the beginning of the series) and then $3^{\circ}$ of flexion due to observed extension of some components, and zero varus/valgus with $3^{\circ}$ posterior slope for the tibial component. Conventional jig alignment technique used intramedullary referencing for the femur and extramedullary for the tibia. The specified bone cuts were: $5^{\circ}$ of valgus and neutral flexion/ extension for the femoral component and zero varus/valgus with $3^{\circ}$ of posterior slope for the tibial component. Length of operation (knife to skin to wound closure) was recorded from the hospital surgical database (Operating Room Scheduling Office System). All patients received three peri-operative doses of prophylactic antibiotics (cefuroxime). A standardised rehabilitation protocol as per local clinical care pathway was used for all patients, with active mobilisation on the first day post-operatively. Length of stay was recorded. Patients were then reviewed at 6 weeks, 6 and 12 months post-operatively.

Ethical approval was obtained from the regional ethics committee (Research Ethics Committee, South East Scotland Research Ethics Service, Scotland, 11/AL/0079) for collection, analysis, and publication of the presented data.

\section{Statistical analysis}

Statistical Package for Social Sciences version 17.0 (SPSS Inc., Chicago, IL, USA) was used to analyse the data.
Parametric and non-parametric tests were used as appropriate to assess continuous variables for significant differences between groups. A Student's $t$ test, unpaired and paired, or Mann Whitney U tests were used to compare linear variables between groups, and Pearson's correlation was used to assess the relationship between linear variables. Dichotomous variables were assessed using a Chi-square test. Multivariable linear regression analyses were used to identify independent predictors of outcome (change in the OKS). A single measure intraclass correlation coefficient was used for the quantification of inter and intra observer reliability of the radiographic measurements. Values greater than 0.75 indicate satisfactory reliability [27]. A $p$ value of $<0.05$ was defined as significant.

A post hoc power calculation was performed using the OKS (primary outcome measure), which has a defined minimal clinically important difference of 4 points [28] and a standard deviation (SD) of 10 points. This determined that 123 patients in the ASM group and 172 patients in the control group achieved a power of 0.92 using two-tailed analysis and an alpha of 0.05 .

\section{Results}

During this period, the senior author performed 398 TKAs of which 295 (74\%) met the inclusion criteria and had preoperative and post-operative outcome measures recorded. There were no significant differences between the groups (Table 1).

Table 1 Patient demographics and pre-operative functional scores according group

\begin{tabular}{|c|c|c|c|c|c|c|c|}
\hline \multirow[t]{2}{*}{ Demographic } & \multirow[t]{2}{*}{ Descriptive } & \multicolumn{2}{|l|}{ Group } & \multirow{2}{*}{$\begin{array}{l}\text { Odds ratio/ } \\
\text { difference }\end{array}$} & \multicolumn{2}{|l|}{$95 \%$ CI } & \multirow[t]{2}{*}{$p$ value } \\
\hline & & $\operatorname{ASM}(n=123)$ & Control $(n=172)$ & & Lower & Upper & \\
\hline \multirow[t]{2}{*}{ Gender $(\mathrm{M} / \mathrm{F})(n, \%$ of group $)$} & Male & 53 & 68 & 1.2 & 0.7 & 1.9 & $0.54 *$ \\
\hline & Female & 70 & 104 & & & & \\
\hline Mean age (years: mean, SD) & & $68.1(10.3)$ & $68.6(10.4)$ & 0.5 & -1.9 & 2.9 & $0.67 * *$ \\
\hline \multirow[t]{5}{*}{ ASA grade ( $n, \%$ of group) } & I & $14(11.4)$ & $12(7.0)$ & - & & & $0.96^{*}$ \\
\hline & II & $103(83.7)$ & $152(88.4)$ & & & & \\
\hline & III & $6(4.9)$ & $8(4.7)$ & & & & \\
\hline & IV & 0 & 0 & & & & \\
\hline & V & 0 & 0 & & & & \\
\hline BMI (mean, SD) & & $31.8(6.5)$ & $30.1(4.9)$ & 1.6 & -2.1 & 5.4 & $0.37 * *$ \\
\hline \multicolumn{8}{|l|}{ PROMs (mean, SD) } \\
\hline OKS & Pre-operative & $19.6(7.6)$ & $18.4(8.5)$ & 1.2 & -0.7 & 3.1 & $0.21 * *$ \\
\hline SF-12 PCS & Pre-operative & $29.8(8.0)$ & $29.0(8.4)$ & 0.8 & -1.1 & 2.7 & $0.73 * *$ \\
\hline SF-12 MCS & Pre-operative & $49.2(12.2)$ & $51.0(11.2)$ & 2.1 & -1.0 & 4.4 & $0.16 * *$ \\
\hline
\end{tabular}

ASM articular surface mounted, $C I$ confidence interval, ASA American Society of Anaesthesiologists, BMI body mass index, PROMs patient reported outcome measures, $O K S$ Oxford knee score, $S F$ short form, PCS physical component summary, MCS mental component summary

*Chi square test

**Unpaired $t$ test 
The inter-observer and intra-observer reliability of radiographic assignment of each of the radiographic measurements were reliable (Table 2). There was no significant difference in the radiographic measures between the groups (Table 3). The spread to the data was, however, much narrower in the ASM group which can be observed by the relatively smaller SD for each of the measurements. Patients in the control group were significantly more like to be outliers for femoral varus/valgus and tibial slope, with a trend towards significance for tibial varus/valgus compare to the ASM group (Table 4). In addition, when combining all outlier data, for any of the four angles measured, only $4 \%$ of patients in the ASM group were outliers compared to $11 \%$ of the control group (Table 4).

There was no significant difference in the OKS or SF-12 scores at one year between the groups (Table 5). Seven patients did not complete their satisfaction rating at one year. The proportion of patients reporting satisfaction with their TKA at one year was $82.4 \%$ (98/119) for the ASM group and $80.5 \%(136 / 169)$ for the control group [odds ratio (OR) $1.1,95 \%$ confidence interval $(\mathrm{CI}) 0.6-2.1, \mathrm{~ns})$.

There was no significant difference in the OKS between outliers $(n=24)$ and those within $3^{\circ}$ of neutral alignment (95\% CI -2.3 to 3.3 , ns). However, there was a greater rate of dissatisfaction in outliers at one year but this was not statistically significant $[33 \%(n=8 / 24)$ versus $17 \%$ $(n=46 / 264)$, OR $2.4,95 \%$ CI $1.0-5.9, \mathrm{~ns}]$.

The mean surgical time for the ASM group was 64 (SD 10) minutes and 59 (SD 11) for the control group (95\% CI -2 to 12 , ns). The median length of stay was 5 days (inter quartile range 4-7). There was a no significant difference in the length of stay between the ASM and control groups (ns). There were no complications from pin sites used to anchor the trackers.

\section{Discussion}

The most important finding of the present study was that ASM navigation is significantly more accurate at achieving the desired component alignment with in a tolerance of 3 degrees compared to conventional non-navigated TKA, with an overall outlier rate of $4 \%$ compared to $11 \%$, respectively. Interestingly, this did not affect the overall functional outcome, according to the OKS, or the rate of patient satisfaction.

Two recent meta-analyses demonstrated conflicting conclusions, with one finding no difference in outlier rate [29] and the other finding a significant improvement in component alignment and clinical outcomes for navigated TKA [30]. Registry data support the use of navigated TKA in

Table 2 Single measure intraclass correlation coefficients for inter- and intra- observer reliability for each of the radiographic measures used

\begin{tabular}{lllllr}
\hline Component & Plane & \multicolumn{2}{l}{ Intraclass correlation coefficient } & \\
\cline { 3 - 5 } & & Inter & $95 \%$ CI & Intra & 0.95 \\
\hline Tibiofemoral angle & & 0.90 & $0.85-0.95$ & 0.90 & $0.92-0.97$ \\
Femoral & Varus/valgus (alpha) & 0.84 & $0.79-0.89$ & 0.86 & $0.86-0.94$ \\
& $\begin{array}{l}\text { Flexion/extension } \\
\text { (gamma) }\end{array}$ & 0.80 & $0.71-0.90$ & 0.88 & $0.80-0.92$ \\
Tibial & Varus/Valgus (beta) & 0.85 & $0.80-0.91$ & 0.85 & $0.86-0.90$ \\
& Tibial slope (sigma) & 0.81 & $0.77-0.85$ & 0.90 \\
\hline
\end{tabular}

CI confidence interval

Table 3 Radiographic measurements according to group

\begin{tabular}{|c|c|c|c|c|}
\hline \multirow[t]{2}{*}{ Component } & \multirow[t]{2}{*}{ Plane } & \multicolumn{2}{|l|}{ Group $\left(^{\circ}\right)$} & \multirow[t]{2}{*}{$p$ value* } \\
\hline & & $\operatorname{ASM}(n=123)$ & Control $(n=172)$ & \\
\hline Tibiofemoral angle (mean, SD) & & $175.4(2.0)$ & $175.1(3.1)$ & ns \\
\hline \multirow[t]{2}{*}{ Femoral (mean, SD) } & Varus/valgus (alpha) & $94.7(1.5)$ & $95.1(3.0)$ & ns \\
\hline & Flexion/extension (gamma) & $0.4(2.3)$ & $3.2(2.4)$ & ns \\
\hline \multirow[t]{2}{*}{ Tibial (mean, SD) } & Varus/Valgus (beta) & $89.9(1.8)$ & $89.8(2.6)$ & ns \\
\hline & Tibial slope (sigma) & $3.2(1.9)$ & $3.3(3.2)$ & ns \\
\hline
\end{tabular}

ASM articular surface mounted

*Unpaired $t$ test 
Table 4 Radiographic measurements illustrating outliers (greater than $3^{\circ}$ ) for each component and in combination according to group

\begin{tabular}{|c|c|c|c|c|c|c|c|}
\hline \multirow[t]{2}{*}{ Component } & \multirow[t]{2}{*}{ Plane } & \multicolumn{2}{|l|}{ Group } & \multirow{2}{*}{$\begin{array}{l}\text { Odds } \\
\text { ratio }\end{array}$} & \multicolumn{2}{|c|}{$95 \% \mathrm{CI}$} & \multirow[t]{2}{*}{$p$ value } \\
\hline & & $\begin{array}{l}\text { ASM } \\
(n=123)\end{array}$ & $\begin{array}{l}\text { Control } \\
(n=172)\end{array}$ & & Lower & Upper & \\
\hline \multirow{2}{*}{$\begin{array}{l}\text { Femoral ( } n, \% \text { of } \\
\text { group) }\end{array}$} & Varus/valgus & $2(1.6)$ & $12(7.0)$ & 4.5 & 1.0 & 20.7 & 0.049 \\
\hline & $\begin{array}{l}\text { Flexion/ } \\
\text { extension }\end{array}$ & $3(2.4)$ & $5(2.9)$ & 1.1 & 0.3 & 5.1 & ns \\
\hline \multirow[t]{2}{*}{ Tibial ( $n, \%$ of group) } & Varus/valgus & $3(2.4)$ & $13(7.6)$ & 3.3 & 0.9 & 11.7 & ns \\
\hline & Tibial slope & $1(0.8)$ & $11(6.4)$ & 8.3 & 1.1 & 65.0 & 0.03 \\
\hline Both ( $n, \%$ of group) & Any & $5(4.1)$ & $19(11.0)$ & 2.9 & 1.1 & 8.1 & 0.03 \\
\hline
\end{tabular}

$A S M$ articular surface mounted, $C I$ confidence interval

*Chi-square test patients less than 65 years of age, with a significantly lower revision rate when compared to conventional TKA [31]. In contrast Parratte et al. [17] demonstrated that patients with a neutral mechanical axis did not have an improved survival rate at 15 years. Despite the conflicting evidence, it is generally accepted that a neutral mechanical axis remains the gold standard [17, 32]. If this is the accepted standard it would appear that computer navigation is a more reliable tool to achieve a neutral mechanical axis. There are, however, recognised surgeon errors in alignment with navigation due to variation in bone cuts [33] and cementing techniques [34, 35].

Ko et al. [36] demonstrated a significant difference in femoral flexion between navigated and non-navigated TKA, finding navigated femoral components to be extended relative to non-navigated components. Our study affirms these findings with a $3^{\circ}$ difference between the ASM and control group. This difference may be explained by the effect of the anterior femoral bow, where an intramedullary jig uses the bow of the distal femur to reference the flexion/extension preparation whereas the navigation

Table 5 Post-operative outcome measures and the difference relative to pre-operative scores according to group

\begin{tabular}{|c|c|c|c|c|c|c|c|}
\hline \multirow{2}{*}{$\begin{array}{l}\text { Functional Meas- } \\
\text { ure }\end{array}$} & \multicolumn{2}{|c|}{$\operatorname{ASM}(n=123)$} & \multicolumn{2}{|c|}{ Control $(n=172)$} & \multirow[t]{2}{*}{ Difference } & \multirow[t]{2}{*}{$95 \% \mathrm{CI}$} & \multirow[t]{2}{*}{$p$ value* } \\
\hline & Mean & SD & Mean & SD & & & \\
\hline \multicolumn{8}{|l|}{ OKS } \\
\hline Pre-operative & 19.8 & 7.7 & 18.4 & 8.5 & 1.2 & -0.7 to 3.1 & ns \\
\hline Post-operative & 32.9 & 10.4 & 33.1 & 10.5 & 0.2 & -2.2 to 2.7 & ns \\
\hline Difference & 13.2 & 8.5 & 14.8 & 10.0 & 1.6 & -0.4 to 3.6 & ns \\
\hline $95 \% \mathrm{CI}$ & $11.6-14.7$ & & $13.5-16.1$ & & & & \\
\hline$p$ value $* *$ & $<0.001$ & & $<0.001$ & & & & \\
\hline \multicolumn{8}{|l|}{ SF-12 PCS } \\
\hline Pre-operative & 29.9 & 8.0 & 28.9 & 8.3 & 0.9 & -1.1 to 2.7 & ns \\
\hline Post-operative & 38.3 & 11.2 & 38.7 & 11.4 & 0.5 & -2.1 to 3.2 & ns \\
\hline Difference & 8.4 & 10.7 & 9.8 & 10.5 & 1.4 & -2.6 to 3.2 & ns \\
\hline $95 \% \mathrm{CI}$ & 6.5 to 10.3 & & 8.3 to 11.4 & & & & \\
\hline$p$ value $* *$ & $<0.001$ & & $<0.001$ & & & & \\
\hline \multicolumn{8}{|l|}{ SF-12 MCS } \\
\hline Pre-operative & 49.4 & 12.3 & 51.0 & 11.2 & 1.7 & -1.0 to 4.4 & ns \\
\hline Post-operative & 50.1 & 10.9 & 51.4 & 10.4 & 1.4 & -1.1 to 3.9 & ns \\
\hline Difference & 0.7 & 12.2 & 0.4 & 12.4 & 0.4 & -1.7 to 4.0 & ns \\
\hline $95 \% \mathrm{CI}$ & -1.2 to 2.5 & & -1.2 to 2.0 & & & & \\
\hline$p$ value $* *$ & ns & & ns & & & & \\
\hline
\end{tabular}

$A S M$ articular surface mounted, $C I$ confidence interval, $O K S$ Oxford knee score, $S F$ short form, $P C S$ physical component summary, $M C S$ mental component summary

*t test

**Paired $t$ test 
Fig. 2 Estimation of degree for femoral flexion, relative to the mechanical axis of the femur required to compensate for anterior femoral bow

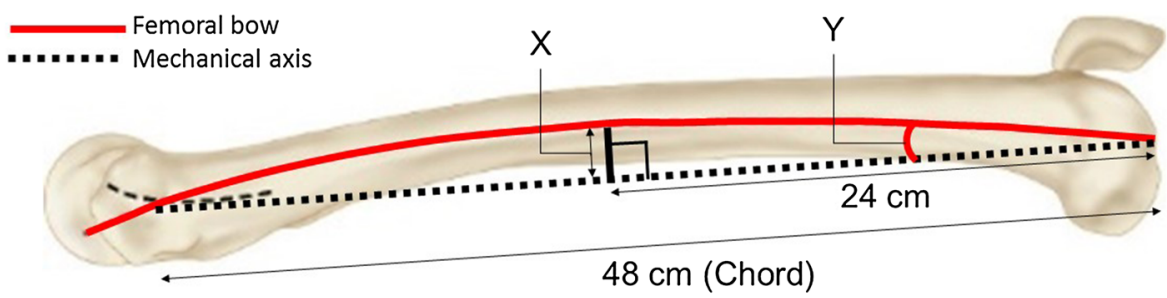

Assumptions:

Average femoral length $48 \mathrm{~cm}$

Average femoral anterior radius (bow) $120 \mathrm{~cm}$

Formulae used:

Chord $=2 v\left(\right.$ radius $[r]^{2}-$ distance centre to chord $\left.[d]^{2}\right)$

Sin $=$ opposite $/$ adjacent
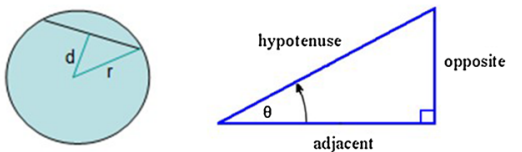

Equation to find $\mathrm{X}$

Chord $=2 v\left(r^{2}-d^{2}\right)$

$48=2 v\left(120^{2}-d^{2}\right)$

$d^{2}=14400-(48 / 2)^{2}$

$d=\sqrt{ } 13824$

$\mathrm{d}=117.6 \mathrm{~cm}$

$\mathrm{X}=\mathrm{r}-\mathrm{d}$

$\mathrm{X}=120-117.6$

$\mathrm{X}=2.4 \mathrm{~cm}$
$\operatorname{Sin} Y=$ opposite $/$ adjacent

$\operatorname{Sin} Y=2.4 / 24.0$

$\operatorname{Sin} Y=0.1$

$Y=5.7$ degrees
Equation to find $\mathrm{Y}$ uses the mechanical axis in the sagittal plane (Fig. 2). If is it is assumed on average the radius of the femur is $120 \mathrm{~cm}$ and the average male femur is $48 \mathrm{~cm}$ in length [16], using trigonometry the distal femoral component should be in $6^{\circ}$ of flexion relative to the mechanical axis to avoid notching the distal femur (Fig. 2). This would, however, change according to the patient characteristics. Although the results from the current study suggest that extension of the femoral component does not influence the functional outcome, this could result in femoral oversizing which is associated with knee stiffness [37].

A major limitation of this study was the use of short leg radiographs to assess component alignment and the tibiofemoral angle. Ethically, it was not indicated to obtain a HKA for all patients and hence is an unavoidable limitation. The circle method used to measure each angle has previously been shown to demonstrate good correlation to those obtained from HKA measurements [24]. The second major limitation was that patients were not prospectively randomised into groups, being dependant on the availability of the ASM trays on the day of surgery. The single surgeon nature of this study is also a limitation, and the results may reflect surgical practice and not the technique. Conversely the consistency of a single surgical approach may be a positive aspect of the study, rather than comparing one surgeon performing ASM with another surgeon using a non-navigation technique as previously described [19].

If the surgeon wants to reduce their number of alignment outliers, then ASM navigated TKA should be considered as a potential tool that improves the reliability of component alignment.

\section{Conclusion}

ASM navigation offers improved accuracy in the placement of both the femoral and tibial components when compared to conventional non-navigation alignment. However, the short-term functional outcome is not influenced by the surgical technique used.

\section{Compliance with ethical standards}

Conflict of interest The authors declare no conflict of interest.

Open Access This article is distributed under the terms of the Creative Commons Attribution 4.0 International License (http:// creativecommons.org/licenses/by/4.0/), which permits unrestricted use, distribution, and reproduction in any medium, provided you give appropriate credit to the original author(s) and the source, provide a link to the Creative Commons license, and indicate if changes were made.

\section{References}

1. Clement ND, Macdonald D, Simpson AH, Burnett R (2013) Total knee replacement in patients with concomitant back pain results in a worse functional outcome and a lower rate of satisfaction. Bone Joint J 95-B:1632-1639

2. Lombardi AV Jr, Berend KR, Adams JB (2014) Why knee replacements fail in 2013: patient, surgeon, or implant?Bone Joint J 96-B:101-104

3. Hernandez-Vaquero D, Noriega-Fernandez A, FernandezCarreira JM, Fernandez-Simon JM, Llorens de los RJ (2014) Computer-assisted surgery improves rotational positioning of the femoral component but not the tibial component in total knee arthroplasty. Knee Surg Sports Traumatol Arthrosc 22:3127-3134 
4. Huang TW, Peng KT, Huang KC, Lee MS, Hsu RW (2014) Differences in component and limb alignment between computerassisted and conventional surgery total knee arthroplasty. Knee Surg Sports Traumatol Arthrosc 22:2954-2961

5. Song EK, Agrawal PR, Kim SK, Seo HY, Seon JK (2016) A randomized controlled clinical and radiological trial about outcomes of navigation-assisted TKA compared to conventional TKA: long-term follow-up. Knee Surg Sports Traumatol Arthrosc 24:3381-3386

6. Picard F, Deep K, Jenny JY (2016) Current state of the art in total knee arthroplasty computer navigation. Knee Surg Sports Traumatol Arthrosc 24:3565-3574

7. Cip J, Widemschek M, Luegmair M, Sheinkop MB, Benesch T, Martin A (2014) Conventional versus computer-assisted technique for total knee arthroplasty: a minimum of 5-year follow-up of 200 patients in a prospective randomized comparative trial. J Arthroplasty 29:1795-1802

8. Hetaimish BM, Khan MM, Simunovic N, Al-Harbi HH, Bhandari M, Zalzal PK (2012) Meta-analysis of navigation vs conventional total knee arthroplasty. J Arthroplasty 27:1177-1182

9. Todesca A, Garro L, Penna M, Bejui-Hugues J (2016) Conventional versus computer-navigated TKA: a prospective randomized study. Knee Surg Sports Traumatol Arthrosc. doi:10.1007/s00167-016-4196-9

10. Chen A, Patel NK, Khan Y, Cobb JP, Gupte CM (2015) The cost of adverse events from knee surgery in the United Kingdom: an in-depth review of the National Health Service Litigation Authority database. Knee 22:286-291

11. Hoke D, Jafari SM, Orozco F, Ong A (2011) Tibial shaft stress fractures resulting from placement of navigation tracker pins. J Arthroplasty 26:504-508

12. Wysocki RW, Sheinkop MB, Virkus WW, Della Valle CJ (2008) Femoral fracture through a previous pin site after computerassisted total knee arthroplasty. J Arthroplasty 23:462-465

13. Lee DH, Padhy D, Lee SH, Nha KW, Park JH, Han SB (2012) Osteoporosis affects component positioning in computer navigation-assisted total knee arthroplasty. Knee 19:203-207

14. Mihalko WM, Duquin T, Axelrod JR, Bayers-Thering M, Krackow KA (2006) Effect of one- and two-pin reference anchoring systems on marker stability during total knee arthroplasty computer navigation. Comput Aided Surg 11:93-98

15. Mihalko WM, Duquin T, Axelrod JR, Fisher L (2007) Location and number of cortical fixation points and the effect on reference base stability during computer-navigated total knee arthroplasty. J Arthroplasty 22:605-608

16. Egol KA, Chang EY, Cvitkovic J, Kummer FJ, Koval KJ (2004) Mismatch of current intramedullary nails with the anterior bow of the femur. J Orthop Trauma 18:410-415

17. Parratte S, Pagnano MW, Trousdale RT, Berry DJ (2010) Effect of postoperative mechanical axis alignment on the fifteen-year survival of modern, cemented total knee replacements. J Bone Joint Surg Am 92:2143-2149

18. Harvie P, Sloan K, Beaver RJ (2011) Three-dimensional component alignment and functional outcome in computer-navigated total knee arthroplasty: a prospective, randomized study comparing two navigation systems. J Arthroplasty 26:1285-1290

19. Shah NA, Patil HG, Dhawale AS, Khedkar BM (2015) Limited femoral navigation versus conventional intramedullary femoral jig based instrumentation for achieving optimal restoration of mechanical axis post total knee arthroplasty: a prospective comparative study of 200 knees. J Arthroplasty 30:559-563

20. Singisetti K, Muthumayandi K, Abual-Rub Z, Weir D (2015) Navigation-assisted versus conventional total knee replacement: no difference in patient-reported outcome measures (PROMs) at 1 and 2 years. Arch Orthop Trauma Surg 135:1595-1601

21. Dawson J, Fitzpatrick R, Murray D, Carr A (1998) Questionnaire on the perceptions of patients about total knee replacement. J Bone Joint Surg Br 80:63-69

22. Ware J Jr, Kosinski M, Keller SD (1996) A 12-Item Short-Form Health Survey: construction of scales and preliminary tests of reliability and validity. Med Care 34:220-233

23. Veljkovic A, Norton A, Salat P, Saltzman C, Femino J, Phisitku 1P, Amendola A (2013) Lateral talar station: a clinically reproducible measure of sagittal talar position. Foot Ankle Int 34:1669-1676

24. Zampogna B, Vasta S, Amendola A, Uribe-Echevarria MB, Gao Y, Papalia R, Denaro V (2015) Assessing Lower Limb Alignment: Comparison of Standard Knee Xray vs Long Leg View. Iowa Orthop J 35:49-54

25. Hamilton DF, Burnett R, Patton JT, Howie CR, Moran M, Simpson AH, Gaston P (2015) Implant design influences patient outcome after total knee arthroplasty: a prospective double-blind randomised controlled trial. Bone Joint J 97-B:64-70

26. Whiteside LA, Arima J (1995) The anteroposterior axis for femoral rotational alignment in valgus total knee arthroplasty. Clin Orthop Relat Res 168-172

27. Bartko JJ (1966) The intraclass correlation coefficient as a measure of reliability. Psychol Rep 19:3-11

28. Clement ND, MacDonald D, Simpson AH (2014) The minimal clinically important difference in the Oxford knee score and Short Form 12 score after total knee arthroplasty. Knee Surg Sports Traumatol Arthrosc 22:1933-1939

29. Shi J, Wei Y, Wang S, Chen F, Wu J, Huang G, Chen J, Wei L, Xia J (2014) Computer navigation and total knee arthroplasty. Orthopedics 37:e39-e43

30. Moskal JT, Capps SG, Mann JW, Scanelli JA (2014) Navigated versus conventional total knee arthroplasty. J Knee Surg 27:235-248

31. deSteiger RN, Liu YL, Graves SE (2015) Computer navigation for total knee arthroplasty reduces revision rate for patients less than sixty-five years of age. J Bone Joint Surg Am 97:635-642

32. Abdel MP, Oussedik S, Parratte S, Lustig S, Haddad FS (2014) Coronal alignment in total knee replacement: historical review, contemporary analysis, and future direction. Bone Joint $\mathrm{J}$ 96-B:857-862

33. Tsukeoka T, Tsuneizumi Y, Yoshino K, Suzuki M (2016) Case-related factors affecting cutting errors of the proximal tibia in total knee arthroplasty assessed by computer navigation. Knee Surg Sports Traumatol Arthrosc. doi:10.1007/ s00167-016-4397-2

34. Chua KH, Chen Y, Lingaraj K (2014) Navigated total knee arthroplasty: is it error-free? Knee Surg Sports Traumatol Arthrosc 22:643-649

35. Seo SS, Kim CW, Lee CR, Seo JH, Kim DH, Kim OG, Min YK (2016) Does final component alignment correlate with alignment of the bone resection surfaces in cemented total knee arthroplasty?Knee Surg Sports Traumatol Arthrosc. doi:10.1007/ s00167-016-4371-z

36. Ko JH, Han CD, Shin KH, Nguku L, Yang IH, Lee WS, Kim KI, Park KK (2016) Femur bowing could be a risk factor for implant flexion in conventional total knee arthroplasty and notching in navigated total knee arthroplasty. Knee Surg Sports Traumatol Arthrosc 24:2476-2482

37. Lo CS, Wang SJ, Wu SS (2003) Knee stiffness on extension caused by an oversized femoral component after total knee arthroplasty: a report of two cases and a review of the literature. J Arthroplasty 18:804-808 